player must choose between two attack possibilities, and since the labels are assumed to attack randomly, the probability of either attack being made is .5. With 24 attacks per label available for analysis, the expected frequency for each chooser-chosen cell was 12 .

Because each $S$ contributed one attack for each of the labels used in his group, only the chi squares within the labels are independent and, therefore, only the chi square for each label was used in the test. The degrees of freedom for each label was one, due to the marginal constraint that the expected frequency be equal to 12. This restriction in analysis is not crucial, because an entire set can be rejected for social-interaction experiments if just one of its labels has a chi square significant at the .05 level.

The most interesting results of the experiment are the chi squares for the two label sets, A-B-C and VAF-ZEG-YAV. The first of these sets was used by Cole (1969) and Viancke et al $(1966,1967)$ and the second by Kline (1968). One label within each of these sets (C and YAV) yielded a significant chi square $(4.16, p<.05)$. Of the remaining labels in both sets, $A$ and $B$ in the first set had completely random behavior patterns, while VAF and ZEG were a little less random with chi squares of $.66(\mathrm{p}>.5)$ and $.16(\mathrm{p}>.75)$, respectively.

The BILL-BOB-BARRY set had the labels (BILL and BOB) with the largest chi square $(6.00, p<.01)$. The other two sets of boys' names and the set of colors all had at least one label with a large enough chi square to be questionable. In each case, the chi square was 2.66 , with a value of 2.71 needed for $\mathrm{p}<.1$.

The two label sets remaining, F E R VID - F R O S T Y - FAR and ARGON-BORON-KRYPTON, had no label with a chi square larger than $.66(\mathrm{p}>.75)$. The entire ARGON-BORON-KRYPTON set had no chi square larger than .16 $(\mathrm{p}>$.75).

Overall, the results of this study indicate that the untested use of labels for the purpose of removing Ss' response biases does not guarantee random choice behavior. The label set used by Cole (1969) and Vinacke et al $(1966,1967)$ and the set used by Kline (1968) were shown, in the present research, to have response biases in the ambiguous all-equal situation. The results of their studies, however, do not present an examination of the degree to which these biases affected behavior when the power of the players differed. However, the mere fact that there are response biases in the ambiguous situation and that response biases may be present in the unambiguous cases is enough to warrant further tests of the labels used in social-interaction experiments.

\section{REFERENCES}

BURGESS, P. M., \& ROBINSON, J. A. Alliances and the theory of collective action: A simulation of coalition processes. In J. N. Rosenau (Ed.), International politics and foreign policy. (Rev. ed.) New York: Free Press, 1969. Pp. 640-650.

COLE, S. G. An examination of the power inversion effect in three person mixed-motive games. Journal of Personality \& Social Psychology, 1969, 11, 50-58.

EBBINGHAUS, H. Uber das Gedachtnis. Translated by $\mathrm{H}$. A. Ruger and C. E. Bussenius as Memory: $A$ contribution to experimental psychology. New York: Dover, 1964.

GLAZE; J. A. The association value of nonsense syllables. Journal of Genetic Psychology, $1928,35,255-269$

GUETZKOW, H. Simulation in the study of inter-nation relations. In $\mathrm{H}$. Guetzkow (Ed.), Stimulation in the social sciences. Englewood Cliffs, N. J: Prentice-Hall, 1962. Pp. 82-93.

HERMANN, C. F., \& HERMANN, M. G. An attempt to simulate the outbreak of World War I. In J. N. Rosenau (Ed.), International politics and foreign policy. (Rev, ed.) New York: Free Press, 1969. Pp. 622-639.

JENKINS, J. J., RUSSELL, W. J., \& SUCI, G. J.
An atlas of semantic profiles for 360 words American Journal of Psychology, 1958, 71, 688-699.

KLINE, D. The effect of bargaining sequence and type of pay-off upon coalition structure and stability in the triad. Technical Report No. 2. Human Learning Research Institute, Michigan State University, 1968

SIEGEL, S. A method for obtaining an ordered metric scale. In S. Messnick and A. H. Brayfield (Eds.), Decision and choice. New York: McGraw-Hill, 1964. Pp. 61-70.

VINACKE, W. E., \& ARKOFF, A. An experimental study of coalitions in the triad. American Sociological Review, 1957, 22, 406-414.

VINACKE, W. E., CROWELL, D. C., DIEN, D., $\&$ YOUNG, $V$. The effect of information about strategy on a three person game. Behavioral Science, 1966, 11, 180-189.

VINACKE, W. E., LICHTMAN, C. M., \& CHERULNIK, P. K. Coalition formation under four different conditions of play in a three person competitive game. Journal of General! Psychology, 1967, 77, 165-176.

$$
\text { NOTES }
$$

1. This research was funded by a grant from the Air Force Office of Scientific Research (F44620-69-C-0114).

2. I am grateful to Dr. James L. Phillips and Dr. Lawrence Messe for their help in preparing this paper.

\title{
Short-term association recall as a function of number and type of retention interval tasks 1
}

C. JAMES SCHEIRER and JAMES F. VOSS, University of Pittsburgh, Pittsburgh, Pa. 15213

In a single-association short-term memory task, four retention-interval activities involving manipulation of numbers were employed, with retention intervals of 32,64 , and $128 \mathrm{sec}$. In the 64and 128-sec intervals, conditions involving two or four tasks of $32 \mathrm{sec}$ each also were employed. The results indicated that number of task shifts in a retention interval did not significantly retard performance and that a number-classification task yielded recall performance significantly superior to addition, subtraction, and counting backwards.
The purpose of the present experiment was to determine if the type of task and the number of shifts in task during the retention interval influence recall performance in a Peterson-type (Peterson \& Peterson, 1959) short-term memory paradigm. That the type of task employed in a retention interval may be a factor in producing differences in recall performance has been demonstrated, e.g., Posner \& Konick (1966). Their results suggested that a classification task involving a relatively high degree of information processing led to poorer recall than other tasks, such as counting backwards or addition, that had a lower processing requirement. The question of whether shifts in the tasks influence forgetting has yet to be 
answered, and the issue is of theoretical importance for the following reason. A trace position, e.g., Broadbent (1962), generally assumes that decay occurs when information subsequent to the stimulus must be processed. Thus, a processing shift is considered to decrease or eliminate rehearsal and produce a retention loss. The question asked in the present experiment is whether additional forgetting occurs if a number of shifts are required. Such a finding would indicate that task shifts in themselves in some way produce forgetting and also would suggest the existence of task interference with a long-term trace. Without even considering a decay position, however, the question of whether number of intervening task shifts may influence the amount of retroactive inhibition is of interest because manipulation of intervening activity in the RI paradigm usually has consisted of presentation of one task. By using one, two, or four task shifts, the hypothesis that retention decreases and number of task shifts increases was tested in the present study. It may be noted that the four tasks employed all involved manipulation of numbers, so that the materials presented under the four different task conditions were highly similar.

\section{METHOD}

The general procedure consisted of presentation of a single association for $2 \mathrm{sec}$, followed by presentation of slides at a 2-sec rate for the duration of the retention interval. After the final slide, an " $X$ " was projected which served as a cue for the recall of the pair. After an intertrial interval of $45 \mathrm{sec}$, the next pair was presented. Sixteen pairs were presented in one experimental session. The general procedure is described elsewhere in more detail (Scheirer \& Voss, 1969).

Six experimental conditions were employed. Three conditions had a retention interval of $128 \mathrm{sec}$, two conditions had a retention interval of $64 \mathrm{sec}$, and one condition had a retention interval of $32 \mathrm{sec}$. The conditions are denoted 128-1, 128-2, 128-4, 64-1, 64-2, $32-1$, with the final number indicating the number of tasks employed during the retention interval. In the case of multiple tasks, each task was of $32 \mathrm{sec}$ duration.

The four tasks used were backward counting, addition, multiplication, and classification. In each task a three-digit number was presented and, respectively, Ss were instructed to count backwards from the number at a 2-sec rate (paced by blank slides), add the three digits mentally and state the sum aloud, multiply the three digits and state the final product aloud, and read the digits from the lowest to the highest digit. The three-digit numbers employed contained neither repeated integers nor the numbers " 0 " or " 1 ." The task $S$ was to perform was indicated by one of four labeled colored lights mounted on a panel directly in front of him.

The Ss were run in five experimental sessions of $1 \mathrm{~h}$ each, with a week elapsing between each session. Each experimental session contained one of the six experimental conditions, with the exception that for each S, Condition 32-1 and Condition 64-1 were run in the same session. The order of the two conditions within the session was counterbalanced. The order of the five sessions was counterbalanced via two randomly permuted 5 by 5 Latin squares.

In the experimental conditions in which one interval task was employed (32-1, 64-1, 128-1), each task was presented four times, with the order counterbalanced according to the four rows of a 4 by 4 Latin square. When two or four tasks were required, they were selected for each presentation by random sampling, with replacement, over the 16 presentations.

The materials consisted of six lists of 16 CVC trigram pairs, constructed via random pairings with minimal item similarity, with each item having an association value of 75\%-95\% (Archer, 1960). The Ss were introductory psychology students at the University of Pittsburgh. The $\mathbf{N}$ was 10 , with each $S$ receiving a total of 96 presentations (16/condition).

\section{RESULTS}

Using correctly recalled pairs, an analysis of variance revealed no significant difference for the experimental condition source of variation, $F(5,40)<1.00$, and no significant difference attributable to ordinal position of the condition, $F(5,40)<1.00$. Orthogonal comparisons revealed that there was no significant difference in performance between the three conditions involving one task and the three conditions involving two or four tasks, $F(1,40)=1.04, p>.05$.

Considering only Conditions 128-1, $128-2$, and $128-4$, there was no significant difference in performance $(F<1.00)$ with means of $10.7,10.9$, and 10.9 , respectively. Thus, with a retention interval activity of $128 \mathrm{sec}$, the number of task shifts did not influence recall. With respect to the 64-1 and 64-2 conditions, the respective mean correct responses were 10.1 and 10.0 with $F<1.00$.

An analysis of variance performed on the $32-1,64-1$, and 128-1 conditions revealed a significant effect of type of task, $F(3,99)=4.45, p<.01$, with orthogonal polynomial comparisons revealing that the classification task yielded performance superior to that of the other conditions, $F(1,99)=12.71, \quad p<.01$. No other comparisons yielded a significant difference. The mean correct recalls for the classification task was 9.3, with the addition, multiplication, and backward-counting tasks yielding mean correct recalls of $6.9,7.4$, and 7.4 , respectively. The retention interval and the Retention Interval by Task interaction sources of variation are not significant, $F(2,99)<1.00$ and $F(6,99)=1.23$, $\mathrm{p}>.05$.

One result, which at first glance appears surprising, was that retention-interval duration yielded no significant performance differences. Previous results, however, suggest that in the present paradigm, forgetting is essentially complete by $8 \mathrm{sec}$ (Scheirer \& Voss, 1969).

$$
\text { DISCUSSION }
$$

The superiority of the classification task in the present experiment is in opposition to the Posner \& Konick (1966) results, which indicated classification to be more difficult than other number manipulation tasks. Their procedure, however, was self-paced, which may account for the discrepancy.

The present results also indicate that shifts in the retention-interval task do not significantly influence recall. There is the possibility that the retention intervals selected are too long to be sensitive to the possible effect of task shifts, especially in view of the previously mentioned lack of an interval in forgetting found beyond $8 \mathrm{sec}$. Based on the present findings, however, it would appear that forgetting is related to the initial processing shift from the stimulus material and not subsequent shifts in the short-term memory situation.

Methodologically, the present findings suggest that the often used counting-backwards task yields performance, at least under the present conditions, approximately equivalent to other number-manipulation tasks, excluding number classification.

\section{REFERENCES}

ARCHER, E. J. A re-valuation of the meaningfulness of all possible CVC trigrams. Psychological Monographs, 1960, 74(10, Whole No. 497).

BROADBENT, D. E. Flow of information within the organism. Journal of Verbal Learning \& Verbal Behavior, 1962, 2, 34-39.

PETERSON, L. R., \& PETERSON, M. Short-term retention of individual verbal items. Journal of Experimental Psychology, 1959, 58, 193-198.

POSNER, M. I, \& KONICK, A. F. On the role of interference in short-term retention. Journal of Experimental Psychology, 1966, 72, 221-231.

SCHEIRER, C. J., \& VOSS, J. F. Reminiscence in short-term memory. Journal of Experimental Psychology, 1969, 80, 262-270. NOTE

1. The present research was supported by the National Institute of Child Growth and Human Development (HD00957-06). 